\title{
Comparison of Fuzzy logic, AHP, FAHP and Hybrid Fuzzy AHP for new supplier selection and its performance analysis
}

\author{
Alessio Ishizaka \\ University of Portsmouth, Portsmouth Business School, Richmond Building, \\ PO1 3ED Portsmouth, United Kingdom \\ Alessio.Ishizaka@port.ac.uk
}

\begin{abstract}
:
The supplier selection exercise is a critical factor towards the success of a company. This paper compares four different methods to support decision makers in selecting the most appropriate supplier. When using Fuzzy logic, the importance of each criterion gets influenced by the level of decomposition in the hierarchical model. Fuzzy logic does not have the capability to measure the level of consistency in the judgments provided by a decision maker. On the other hand, Analytic Hierarchy Process (AHP) cannot capture subjectivity (or fuzziness) of human judgments as the verbal assessments are converted into crisp values. Fuzzy Analytic Hierarchy Process (FAHP) is a merger of the two methods, Fuzzy logic and the Analytic Hierarchy Process (AHP), which inherits the advantages of both and, therefore, addresses the above mentioned problems. The FAHP method is useful in identifying a suitable supplier and to evaluate its performance as demonstrated in the described case study. It can also be applied in any other selection or ranking problem. Finally, we introduce the Hybrid Fuzzy AHP, which can handle direct or pairwise, crisp or fuzzy evaluations.
\end{abstract}

Keywords: Supplier evaluation, Analytic Hierarchy Process, Fuzzy logic, Fuzzy Analytic Hierarchy Process, Hybrid Fuzzy AHP, Consistency

\section{Introduction}

Suppliers are of tremendous importance to their clients. This importance is accentuated with the pressure to reduce the supply base (Ogden, 2006, Sarkar and Mohapatra, 2006). Wrong supplier selection may lead to serious consequences. Hoecht and Trott (2006) listed several problems due to poor supplier and unhealthy buyer-supplier relationships. Recent surveys highlight the importance given to this process (Lieb and Bentz, 2005, Lieb and Bentz, 2006, Lieb and Butner, 2007), and the analysis of criteria for selecting suppliers and measuring their performance has been the focus of many researchers. The multi-criteria nature of the problem was recognised very early by Dickson (1966) who sent a questionnaire to 273 purchasing agents and managers (selected from the membership list of the National Association of Purchasing Managers). The subjects were asked to rank 23 criteria. The most important criteria discovered were quality, on-time delivery, performance history and the warranty offered by their suppliers. In 1991, Weber et al. (1991) enumerated all papers published since 1966 according to the Dickson's criteria. The 23 criteria of Dickson still cover the majority of criteria presented in the 74 reviewed papers. Cheraghi et al. (2004) 
reviewed 110 papers from 1990 to 2001. In both studies, net price, delivery and quality are the most cited criteria. However, Cheraghi et al. (2004)'s work found several new criteria. The supplier selection process is therefore more than ever a multi-criteria decision problem and a complex one. This problem has been extensively studied in literature. Several papers have reviewed the techniques applied for this exercise (Aissaoui et al., 2007, de Boer et al., 2001, Ho, 2008, El-Sawalhi et al., 2007, Bruno et al., 2012, Chai et al., 2013). Among these, Analytic Hierarchy Process (AHP) has been the most widely used technique. A recent trend is to use fuzzy sets to take into account the uncertainties (Chai et al., 2013) and also to integrate it with AHP (Bruno et al., 2012). As a consequence, a debate has arisen over the best method for selecting a supplier. Ordoobadi (2009) advocates Fuzzy logic, whereas Labib (2011) prefers AHP.

Ordoobadi (2009) observes that a common characteristic of all selection methods is to produce a ranking based on two factors: the supplier performance on decision criteria and the relative weight of these criteria. Both factors may be subjective, especially for qualitative criteria, and therefore are specific to the decision-maker. Often, the evaluation process requires that the decision-maker express his/her preferences on a numeric scale. Several authors (Nakandala et al., 2013, Ganga and Carpinetti, 2011, Amindoust et al., 2012, Altinoz, 2008) claim that the main problem in this elicitation is that the subjectivity and uncertainty associated with the perceptions are lost by forcing the decision maker into a numeric scale. Therefore, Ordoobadi (2009) proposes to use Fuzzy logic in order to express preferences in linguistic terms. Labib (2011) agrees with the importance of linguistic appreciations but he defends the use of AHP for three reasons:-

- The final ranking is equal to the unity.

- A sensitivity analysis is possible.

- A measure of inconsistency of the user's preferences is available.

In this paper, we first review the two methods of Fuzzy Logic and AHP in Section 2. Section 3 describes Fuzzy AHP which combines Fuzzy logic with AHP and claims that the advantages of both methods are inherited. Section 4 then proposes the Hybrid Fuzzy AHP approach to evaluate performances of suppliers. Finally, the paper concludes with a summary and suggestions for future research.

\section{Supplier selection}

\subsection{Introduction to the problem}

The two main aspects of the supplier selection process are 1) the selection of criteria for taking decisions, and 2) choosing a method for ranking the available suppliers. This paper focuses on the second part where a method is chosen to rank the available options. In order to compare the ranking methods, our approach applies these methods to the same problem and 
then analyse their outputs. For this reason, we selected the case study that was first introduced by (Ordoobadi, 2009) and then reused by (Labib, 2011) for comparison.

A fictitious company XYZ Co is faced with the task to select a supplier from the three suppliers: A, B and C. The selection process will be based on the hierarchy of criteria defined in Figure 1. The relative weights given to these criteria are provided on a linguistic performance scale (Table 1) and can be found in brackets in Figure 1. The performance of each supplier in regards to each criterion is given in Table 3 using a linguistic performance scale (Table 2). These evaluations are often given by the procurement manager or procurement team in a consensual evaluation after site visits, interview of the considered suppliers and, sometimes, meeting with the previous customers of these suppliers. An example of such evaluation process is given in (Ishizaka et al., 2012). The goal of this paper is not to collect such type of evaluation but to discuss how these evaluations can be analysed. Therefore, in order to have a fair comparison, we have reused the data of (Ordoobadi, 2009) and (Labib, 2011). In order to convert the linguistic evaluation into a numeric scale, Ordoobadi (2009) uses Fuzzy logic and Labib (2011) prefers AHP. The next sections will detail both methods. 
[Post-print version] Please cite as: Alessio Ishizaka, Comparison of Fuzzy logic, AHP, FAHP and Hybrid Fuzzy AHP for new supplier selection and its performance analysis, International Journal of Integrated Supply Management, 9(1/2), 1-22, 2014

\section{Level 1: \\ Level 2: \\ Level 3: \\ Goal \\ Criteria \\ Sub-criteria \\ Level 4: \\ Sub-Sub-criteria \\ Weights}

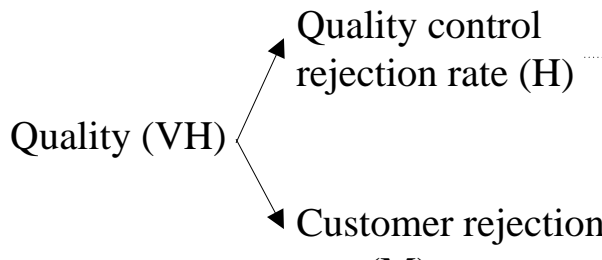

rate $(\mathrm{M})$
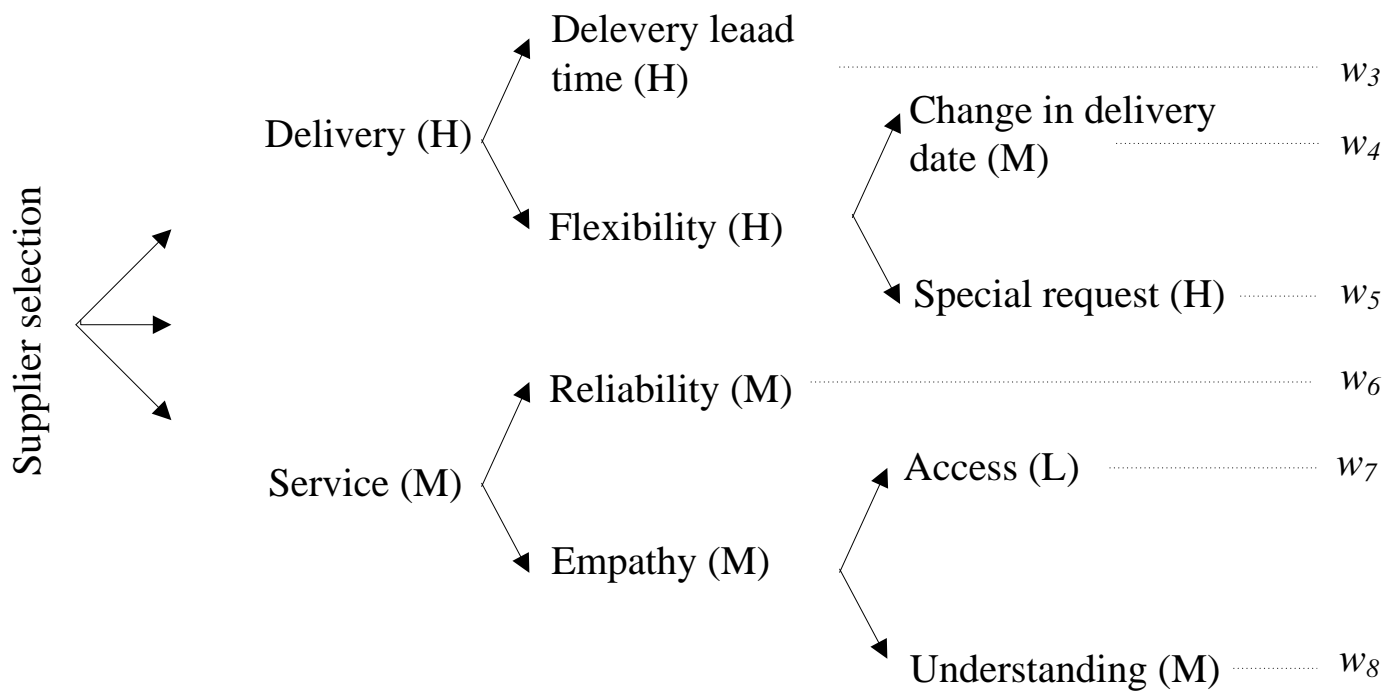

Purchase price $(\mathrm{VH})$

$w_{9}$

Costs $(\mathrm{H})$

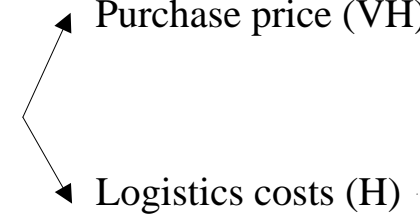

$w_{10}$

Figure 1: Supplier selection problem of Ordoobadi (2009)

\begin{tabular}{|c|c|}
\hline Linguistic importance scale & Fuzzy importance \\
\hline Low importance (L) & $(0.0,0.0,0.2,0.4)$ \\
\hline Moderate importance $(\mathrm{M})$ & $(0.2,0.4,0.4,0.6)$ \\
\hline High importance $(\mathrm{H})$ & $(0.4,0.6,0.6,0.8)$ \\
\hline Very high importance $(\mathrm{VH})$ & $(0.6,0.8,1.0,1.0)$ \\
\hline
\end{tabular}


Table 1: Linguistic importance scale

\begin{tabular}{|c|c|}
\hline Linguistic performance scale & Fuzzy performance \\
\hline Poor performance $(\mathrm{P})$ & $(0,0,2,4)$ \\
\hline Good performance $(\mathrm{G})$ & $(2,4,4,6)$ \\
\hline Very good performance $(\mathrm{VG})$ & $(4,6,6,8)$ \\
\hline Excellent performance $(\mathrm{EX})$ & $(6,8,10,10)$ \\
\hline
\end{tabular}

Table 2: Linguistic performance scale

\begin{tabular}{|l|c|c|c|}
\hline \multicolumn{1}{|c|}{ Selection criteria } & Supplier A & Supplier B & Supplier C \\
\hline Customer reject rate & G & EX & VG \\
\hline Quality control reject rate & VG & VG & G \\
\hline Delivery lead time & P & G & P \\
\hline Change in delivery date & EX & P & VG \\
\hline Special requests & G & P & VG \\
\hline Reliability & P & G & EX \\
\hline Access & VG & EX & P \\
\hline Understanding & G & P & G \\
\hline Purchase price & P & G & G \\
\hline Logistics costs & VG & G & P \\
\hline
\end{tabular}

Table 3: Suppliers' performance ratings

\subsection{Fuzzy logic}

Linguistic judgements may depict different levels of importance for different persons. Fuzzy logic is often used (Zadeh, 1965) to capture this variation in the level of importance,. The degree of membership is given by a membership function, which is usually depicted on two axis diagram. The horizontal axis represents the domain elements of the fuzzy sets and the vertical axis represents the degree of membership, where zero means non-membership and one implies full membership. The membership function can be formulated in different ways, for example, using linear, S-curves, triangular or trapezoidal representations. Figure 2 represents the membership functions of the linguistic importance scale, taken from (Ordoobadi, 2009). 
[Post-print version] Please cite as: Alessio Ishizaka, Comparison of Fuzzy logic, AHP, FAHP and Hybrid Fuzzy AHP for new supplier selection and its performance analysis, International Journal of Integrated Supply Management, 9(1/2), 1-22, 2014

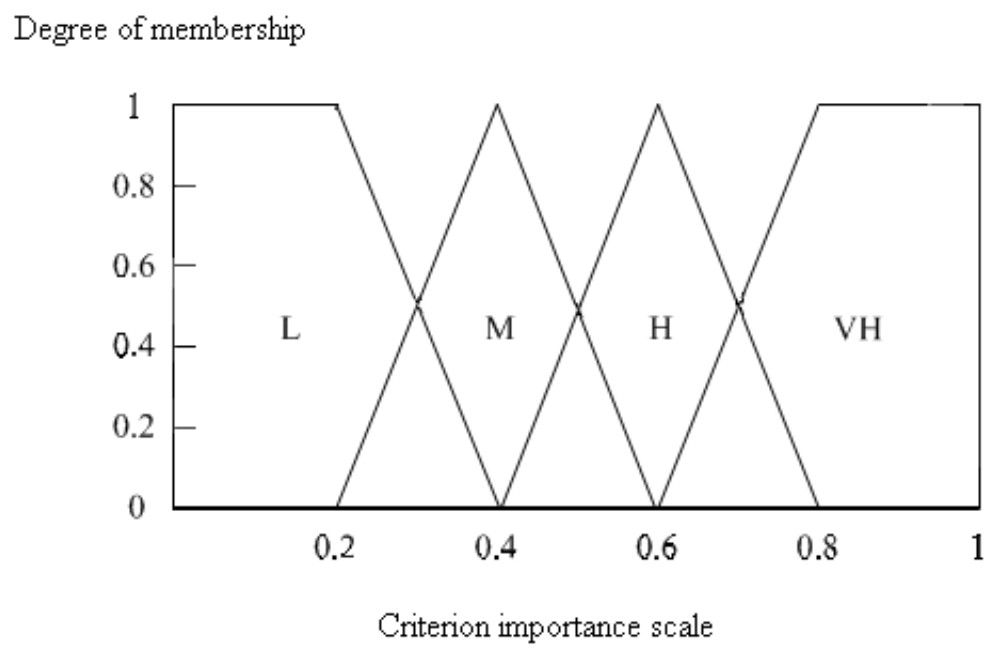

Figure 2: Membership functions of the linguistic importance weight (Ordoobadi, 2009)

The triangular and trapezoidal functions are the most frequently used membership functions. They can be denoted by $\tilde{\mathrm{A}}=\left(1, \mathrm{~m}_{1}, \mathrm{~m}_{\mathrm{u}}, \mathrm{u}\right)$, where $1 \leq \mathrm{m}_{1} \leq \mathrm{m}_{\mathrm{u}} \leq \mathrm{u}$ correspond to lower, modallower, modal-upper and upper bound, i.e. the trapezium's angle points (Figure 3 ). If the membership is triangular, then $\mathrm{m}_{\mathrm{l}}=\mathrm{m}_{\mathrm{u}}$. The membership of $\tilde{\mathrm{A}}$ is defined by:

$$
\mu_{\tilde{A}}(x)=\left\{\begin{array}{cl}
\frac{x-l}{m_{l}-l}, & l \leq x \leq m_{l} \\
1, & m_{l}<x<m_{u} \\
\frac{u-x}{u-m_{u}}, & m_{u}<x<u \\
0, & \text { otherwise }
\end{array}\right.
$$

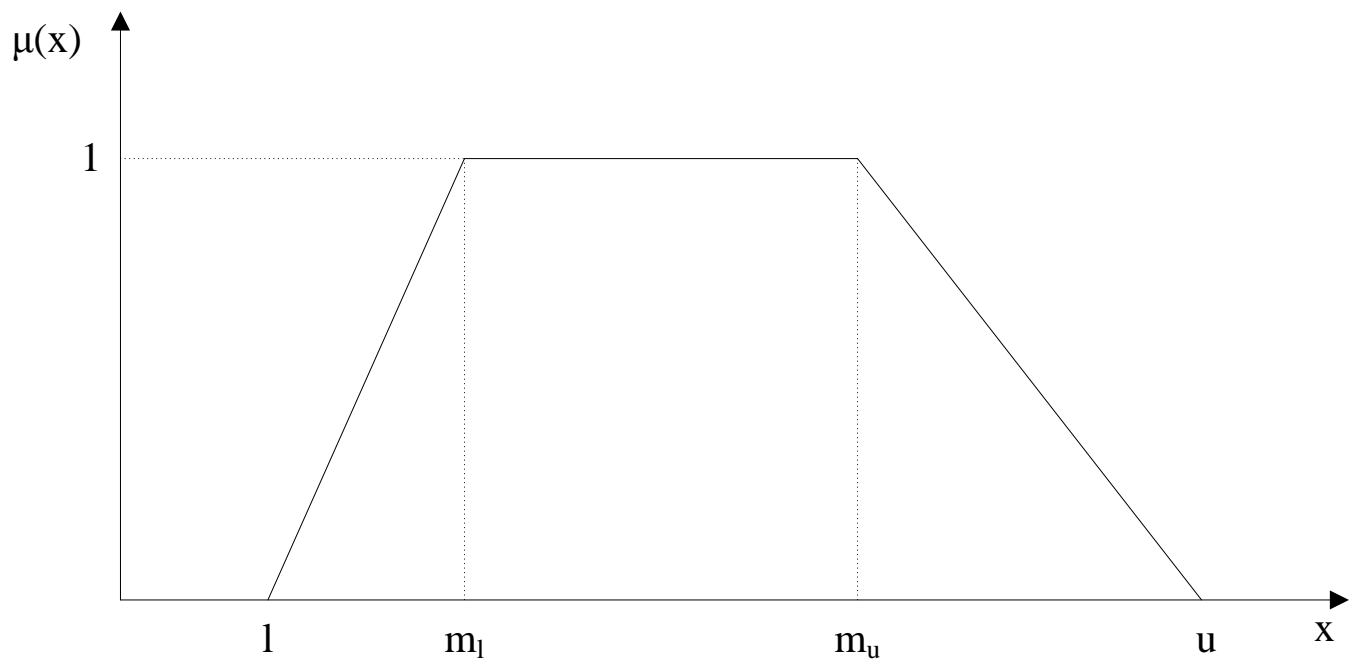

Figure 3: Trapezoidal membership function 
[Post-print version] Please cite as: Alessio Ishizaka, Comparison of Fuzzy logic, AHP, FAHP and Hybrid Fuzzy AHP for new supplier selection and its performance analysis, International Journal of Integrated Supply Management, 9(1/2), 1-22, 2014

The fuzzy weight of a branch (Figure 1) is calculated by multiplying the evaluation on each node of that branch. For example, $w_{1}$ is calculated by multiplying the importance of Quality $(\mathrm{VH})$ by the evaluation of the Quality control rejection rate $(\mathrm{H})$. Thus, $w_{l}=\mathrm{VH} \cdot \mathrm{H}=(0.6$, $0.8,1.0,1.0) \cdot(0.4,0.6,0.6,0.8)=(0.24,0.48,0.6,0.8)$. The other weights are calculated in the same manner:

$$
\begin{aligned}
& w_{1}=(0.24,0.48,0.6,0.8) \\
& w_{2}=(0.12,0.32,0.4,0.6) \\
& w_{3}=(0.16,0.36,0.36,0.64) \\
& w_{4}=(0.032,0.144,0.144,0.384) \\
& w_{5}=(0.064,0.216,0.216,0.512) \\
& w_{6}=(0.04,0.16,0.16,0.36) \\
& w_{7}=(0,0,0.032,0.144) \\
& w_{8}=(0.008,0.064,0.064,0.216) \\
& w_{9}=(0.24,0.48,0.6,0.8) \\
& w_{10}=(0.16,0.36,0.36,0.64)
\end{aligned}
$$

Using the suppliers' performance ratings (Table 3) and the fuzzy performance (Table 2), we can construct the fuzzy supplier performances table (Table 4).

\begin{tabular}{|l|c|c|c|}
\hline & Supplier A & Supplier B & Supplier C \\
\hline Customer reject rate & $(2,4,4,6)$ & $(6,8,10,10)$ & $(4,6,6,8)$ \\
\hline Quality control reject rate & $(4,6,6,8)$ & $(4,6,6,8)$ & $(2,4,4,6)$ \\
\hline Delivery lead time & $(0,0,2,4)$ & $(2,4,4,6)$ & $(0,0,2,4)$ \\
\hline Change in delivery date & $(6,8,10,10)$ & $(0,0,2,4)$ & $(4,6,6,8)$ \\
\hline Special requests & $(2,4,4,6)$ & $(0,0,2,4)$ & $(4,6,6,8)$ \\
\hline Reliability & $(0,0,2,4)$ & $(2,4,4,6)$ & $(6,8,10,10)$ \\
\hline Access & $(4,6,6,8)$ & $(6,8,10,10)$ & $(0,0,2,4)$ \\
\hline Understanding & $(2,4,4,6)$ & $(0,0,2,4)$ & $(2,4,4,6)$ \\
\hline Purchase price & $(0,0,2,4)$ & $(2,4,4,6)$ & $(2,4,4,6)$ \\
\hline Logistics costs & $(4,6,6,8)$ & $(2,4,4,6)$ & $(0,0,2,4)$ \\
\hline
\end{tabular}

Table 4: Fuzzy supplier performances

The fuzzy scores of the alternatives (second column of Table 5) are obtained by multiplying the fuzzy performances (Table 4 ) by the fuzzy importance weights $w_{i}$ in a weighted sum.

These fuzzy scores are defuzzified and converted to crisp scores by the centre of area method (or centroid):

$\bar{x}=\frac{l+m_{l}+m_{u}+u}{4}$ 
[Post-print version] Please cite as: Alessio Ishizaka, Comparison of Fuzzy logic, AHP, FAHP and Hybrid Fuzzy AHP for new supplier selection and its performance analysis, International Journal of Integrated Supply Management, 9(1/2), 1-22, 2014

For example, the crisp score of supplier A is $S_{a}=(1.936+8.272+11.952+31.28) / 4=13.36$ (third column of Table 5).

\begin{tabular}{|l|c|c|c|c|}
\hline Alternatives & Fuzzy scores & $\begin{array}{c}\text { Crisp } \\
\text { scores }\end{array}$ & $\begin{array}{c}\text { Normalised crisp } \\
\text { scores }\end{array}$ & Rank \\
\hline Supplier A & $(1.936,8.272,11.952,31.28)$ & 13.36 & 0.306 & 3 \\
\hline Supplier B & $(\mathbf{3 . 1 2}, \mathbf{1 1 . 2 , 1 5 . 4 8 8 , 3 3 . 3 2 8 )}$ & 15.78 & 0.362 & 1 \\
\hline Supplier C & $(2.32,9.776,13.12,32.56)$ & 14.44 & 0.331 & 2 \\
\hline
\end{tabular}

Table 5: Fuzzy, crisp, normalised scores and supplier rankings

Labib (2011) argued that 1) the summation of these crisp scores is not equal to unity (third column of Table 5), 2) sensitivity analysis cannot be performed, and 3) a consistency measure is not possible. We can see in Table 5 (fourth column) that the first argument is false: scores can be normalised to unity. The second argument is also incorrect: sensitivity analysis helps in understanding the causal relationship among criteria and final scores is possible, and even several types of sensitivity analysis exist (Thomaidis et al., 2006). The analyst can experiment by changing:

- the form of the membership functions (singleton, triangular, trapezoidal, non-linear Gaussian, asymmetric, etc.),

- the position of the membership function,

- the linguistic appreciation associated to a criteria or alternative.

For example, if we consider that the criteria "Reliability" receives the same weight as the criteria "Quality control rejection rate" (i.e. $w_{6}=w_{1}$ ), then the supplier C becomes slightly better than supplier B (Table 6).

\begin{tabular}{|l|c|c|c|c|}
\hline Alternatives & Fuzzy scores & Crisp scores & $\begin{array}{c}\text { Normalised } \\
\text { crisp scores }\end{array}$ & Rank \\
\hline Supplier A & $(1.936,8.272,12.832,33.04)$ & 14.02 & 0.287 & 3 \\
\hline Supplier B & $(3.52,12.48,17.248,35.968)$ & 17.30 & 0.354 & 2 \\
\hline Supplier C & $(3.52,12.336,17.52,36.96)$ & 17.58 & 0.359 & 1 \\
\hline
\end{tabular}

Table 6: New results after a sensitivity analysis

The last criticism of Labib is correct. Because there is no redundancy in the evaluations, we cannot cross-check the consistency of the decision-maker.

Another problem of Fuzzy logic that was not mentioned by Labib is the distortion of parent node score with the introduction of a further hierarchy level. For example, in Figure 1, the branch "Delivery" is split into "Delivery lead time" and "Flexibility". If the branches were stopped at this level, both criteria would receive the same score $w_{3}=(0.16,0.36,0.36,0.64)$ 
as both have the same rating. However, the criterion "Flexibility" is further decomposed into "Change in delivery date" $(\mathrm{M})$ and "Special requests" $(\mathrm{H})$. By multiplying $w_{3}$ by the respective node weights, we obtain $w_{4}=(0.032,0.144,0.144,0.384)$ and $w_{5}=(0.064,0.216$, $0.216,0.512)$. But, if we add the scores of $w_{4}$ and $w_{5}$, we obtain $(0.104,0.376,0.376,0.872)$, which is different than the initial parent node weight $w_{3}$ without the addition of a further level.

The dependency of the weights to the depth of the hierarchy and the consistency measure issue can be solved in AHP as explained in the next section.

\subsection{AHP}

AHP has been often used for supplier selection (Gaudenzi and Borghesi, 2006, Ounnar and Pujo, 2005, Meixell and Norbis, 2008, Ishizaka, 2012). As with the Fuzzy logic method, AHP also formulates the problem in a hierarchical structure (see Figure 1 for example). The main difference is the elicitation of relative weights (importance) of the criteria and performances of the alternatives through pairwise comparisons, which are collected in a comparison matrix A (Saaty, 1977, Saaty, 1980, Ishizaka and Labib, 2011). The weights and performances (local priorities) are derived from this matrix $\mathbf{A}$ by using the Eigenvector method:

$$
\mathbf{A} \cdot \mathbf{p}=\lambda_{\max } \cdot \mathbf{p}
$$

where $\mathbf{A}$ is the comparison matrix

p is the priorities vector

$\lambda_{\max }$ is the maximal eigenvalue

The maximal eigenvalue is also use to calculate the consistency index:

$$
\mathrm{CI}=\frac{\lambda_{\max }-n}{n-1},
$$

where $n=$ dimension of the matrix

$\lambda_{\max }=$ maximal eigenvalue

If CR, the ratio of CI and RI (an average CI of 500 randomly filled matrices of same dimension), is less than $10 \%$, then the evaluations of the decision maker can be considered as having an acceptable consistency.

$$
\mathrm{CR}=\mathrm{CI} / \mathrm{RI}
$$

where $\mathrm{CR}$ is the consistency ratio

$\mathrm{RI}$ is the random index

Saaty (1977) calculated the random indices given in Table 7.

\begin{tabular}{|l|c|c|c|c|c|c|c|c|}
\hline$n$ & 3 & 4 & 5 & 6 & 7 & 8 & 9 & 10 \\
\hline RI & 0.58 & 0.9 & 1.12 & 1.24 & 1.32 & 1.41 & 1.45 & 1.49 \\
\hline
\end{tabular}

Table 7: Random indices 
[Post-print version] Please cite as: Alessio Ishizaka, Comparison of Fuzzy logic, AHP, FAHP and Hybrid Fuzzy AHP for new supplier selection and its performance analysis, International Journal of Integrated Supply Management, 9(1/2), 1-22, 2014

In order to convert the linguistic scales (Table 1 and Table 2) into pairwise comparisons, Labib (2011) used the arbitrary mapping of Table 8 for the importance scale and Table 9 for the performance scale. By introducing the pairwise comparisons of Table 8 and Table 9 in the comparison matrices (e.g. Table 10 for the criteria) and using the formula (3), we calculate the weights and the local priorities. Figure 4 shows the criteria hierarchy in Expert Choice with the weights in brackets similarly as in Figure 1. Finally, by multiplying the weights and the local priorities, we obtain the global priorities (Table 11).

\begin{tabular}{|c|c|}
\hline Pairwise comparison of linguistic importance levels & AHP evaluation \\
\hline VH/H & 2 \\
\hline VH/M & 4 \\
\hline VH/L & 6 \\
\hline H/M & 2 \\
\hline H/L & 4 \\
\hline M/L & 2 \\
\hline
\end{tabular}

Table 8: Pairwise comparison of the linguistic importance scale

\begin{tabular}{|c|c|}
\hline Pairwise comparison of linguistic performance levels & AHP evaluation \\
\hline EX/VG & 2 \\
\hline EX/G & 4 \\
\hline EX/P & 6 \\
\hline VG/G & 2 \\
\hline VG/P & 4 \\
\hline G/P & 2 \\
\hline
\end{tabular}

Table 9: Pairwise comparison of the linguistic performance scale

\begin{tabular}{|l|c|c|c|c|}
\hline & Quality $(\mathrm{VH})$ & Delivery $(\mathrm{H})$ & Service $(\mathrm{M})$ & Cost $(\mathrm{H})$ \\
\hline Quality $(\mathrm{VH})$ & 1 & 2 & 4 & 2 \\
\hline Delivery $(\mathrm{H})$ & $1 / 2$ & 1 & 2 & 1 \\
\hline Service $(\mathrm{M})$ & $1 / 4$ & $1 / 2$ & 1 & $1 / 2$ \\
\hline Cost $(\mathrm{H})$ & $1 / 2$ & 1 & 2 & 1 \\
\hline
\end{tabular}

Table 10: Comparisons matrix of the criteria 


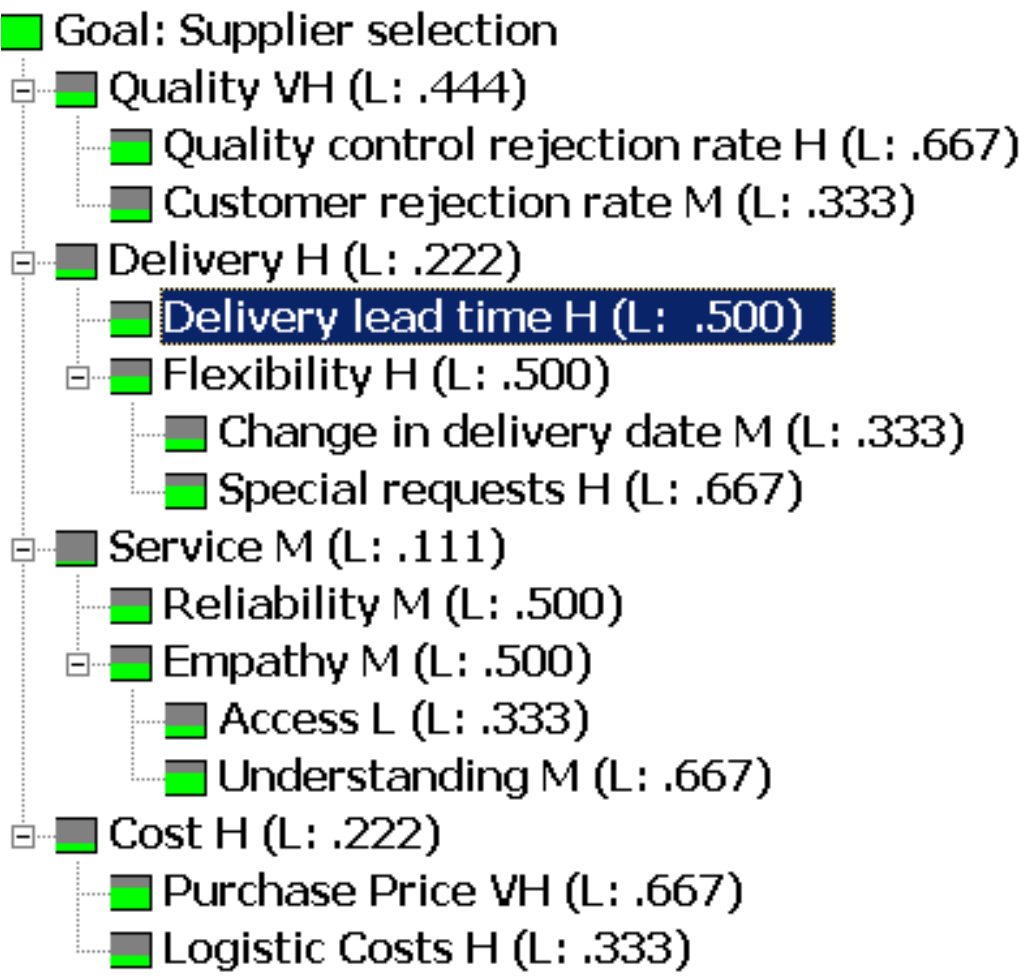

Figure 4: Criteria weights based on the case study of (Ordoobadi, 2009) in Expert Choice

Table 11: Overall ranking of the suppliers

\begin{tabular}{|c|c|}
\hline Supplier & Priority \\
\hline Supplier A & 0.277 \\
\hline Supplier B & 0.407 \\
\hline Supplier C & 0.316 \\
\hline
\end{tabular}

AHP, unlike the Fuzzy logic method (section 2.2), has criteria weights which are independent from the depth of the hierarchy. This property holds because the sum of local siblings' weights on each level is always equal to 1 . We use Figure 4 to illustrate this independence. The siblings" criteria "Delivery lead time" and "Flexibility" have the same local weight of 0.5 . The criterion "Flexibility" is further subdivided into "Change in delivery date" and "Special request". The criterion "Delivery lead time" does not have any further branches. The leaf weights for the two sub-criteria are:

- "Change in delivery date": $0.222 \cdot 0.5 \cdot 0.333=0.036963$

- "Special request": $0.222 \cdot 0.5 \cdot 0.667=0.074037$

The sum of the two sub-criteria weights is 0.111 . This is equivalent to weight of the criterion "Delivery lead time" and the weight of its sibling "Flexibility": $0.222 \cdot 0.5=0.111$. This invariance of weights to the depth of the hierarchy holds because the sum of the local weights of the criteria "Change in delivery date" and "Special request" is equal to unity: $0.333+$ 
$0.667=1$. Therefore, in AHP, the addition of a hierarchical level does not alter the weights as in Fuzzy logic (recall Sub-section 2.2). Another advantage of AHP, mentioned by Labib (2011), is the possibility to cross-check consistency with (4).

AHP assumes that the decision maker is able to provide exact assessments when comparing criteria and alternatives. However, due to uncertainty, incompleteness and subjectivity of the information, it is difficult to provide exact judgements. AHP, like other classical decisionmaking methods, has been criticised for simplifying the decision process by forcing the decision maker to express their view on crisp numeric scale (Van Laarhoven and Pedrycz, 1983, Zheng et al., 2012, Ho, 2012, Piltan et al., 2012). Verbal judgements may mean different level of importance for different persons. It is for this reason that different numeric scales have been proposed to convert the verbal appreciations (Ishizaka et al., 2006) but this still leave the decision maker with the unsolved problem of the choice of the correct numeric scale. In the next section, we will show how the advantages of both presented methods are merged in the Fuzzy AHP.

\subsection{Fuzzy AHP}

This approach was introduced by Laarhoven and Pedrycz (1983). The Fuzzy AHP method is identical to the traditional AHP (section 2.3) at the exception of the conversion of the verbal appreciation into the numeric scale (He et al., 2012). The procedure is based the following steps:

\section{a) Develop a hierarchical structure}

This step is identical to the two previous methods (Figure 1).

\section{b) Define the Fuzzy judgments}

In order to capture vagueness, imprecision and uncertainty of the linguistic scale, Table 8 and Table 9 are converted into fuzzy numbers.

The ratio of two fuzzy numbers $\tilde{\mathrm{A}}_{1}=\left(\mathrm{l}_{1}, \mathrm{~m}_{11}, \mathrm{~m}_{\mathrm{u} 1}, \mathrm{u}_{1}\right)$ and $\tilde{\mathrm{A}}_{2}=\left(\mathrm{l}_{2}, \mathrm{~m}_{12}, \mathrm{~m}_{\mathrm{u} 2}, \mathrm{u}_{2}\right)$ is given by:

$\left(\mathrm{l}_{1}, \mathrm{~m}_{11}, \mathrm{~m}_{\mathrm{u} 1}, \mathrm{u}_{1}\right) /\left(\mathrm{l}_{2}, \mathrm{~m}_{12}, \mathrm{~m}_{\mathrm{u} 2}, \mathrm{u}_{2}\right)=\left(\min \left(\mathrm{l}_{1} / \mathrm{u}_{2}, \mathrm{u}_{1} / \mathrm{l}_{2}\right), \min \left(\mathrm{m}_{11} / \mathrm{m}_{\mathrm{u} 2}, \mathrm{~m}_{\mathrm{u} 1} / \mathrm{m}_{12}\right), \max \right.$ $\left.\left(\mathrm{m}_{11} / \mathrm{m}_{\mathrm{u} 2}, \mathrm{~m}_{\mathrm{u} 1} / \mathrm{m}_{12}\right), \max \left(\mathrm{l}_{1} / \mathrm{u}_{2}, \mathrm{u}_{1} / \mathrm{l}_{2}\right)\right)$

By using the fuzzy numbers of Table 1 and Table 2, we obtain the ratios given in Table 12 and Table 13. In order to respect the 1-9 Saaty scale, a division by 0 implying an infinite number is replaced by the value 9 (maximum in the Saaty scale) and results below 1 are replaced by 1 (the minimum in the Saaty scale). 
[Post-print version] Please cite as: Alessio Ishizaka, Comparison of Fuzzy logic, AHP, FAHP and Hybrid Fuzzy AHP for new supplier selection and its performance analysis, International Journal of Integrated Supply Management, 9(1/2), 1-22, 2014

\begin{tabular}{|c|c|}
\hline $\begin{array}{c}\text { Pairwise comparison of linguistic importance } \\
\text { levels }\end{array}$ & $\begin{array}{c}\text { Fuzzy AHP } \\
\text { evaluation }\end{array}$ \\
\hline $\mathrm{VH} / \mathrm{H}$ & $(1,1.333,1.667,2.5)$ \\
\hline $\mathrm{VH} / \mathrm{M}$ & $(1,2,2.5,5)$ \\
\hline $\mathrm{VH} / \mathrm{L}$ & $(1.5,5,9,9)$ \\
\hline $\mathrm{H} / \mathrm{M}$ & $(1,1.5,1.5,4)$ \\
\hline $\mathrm{H} / \mathrm{L}$ & $(1,3,9,9)$ \\
\hline $\mathrm{M} / \mathrm{L}$ & $(1,2,9,9)$ \\
\hline
\end{tabular}

Table 12: Fuzzy pairwise comparison of the linguistic importance scale

\begin{tabular}{|c|c|}
\hline $\begin{array}{c}\text { Pairwise comparison of linguistic } \\
\text { performance levels }\end{array}$ & $\begin{array}{c}\text { Fuzzy AHP } \\
\text { evaluation }\end{array}$ \\
\hline EX/VG & $(1,1.333,1.667,2.5)$ \\
\hline EX/G & $(1,2,2.5,5)$ \\
\hline EX/P & $(1.5,5,9,9)$ \\
\hline VG/G & $(1,1.5,1.5,4)$ \\
\hline VG/P & $(1,3,9,9)$ \\
\hline G/P & $(1,2,9,9)$ \\
\hline
\end{tabular}

Table 13: Fuzzy pairwise comparison of the linguistic performance scale

c) Fuzzy weights

The criteria have received a linguistic evaluation (Figure 1). This linguistic evaluation is transformed into a pairwise comparison (Table 12) and inserted into the comparison matrix (Table 14). For example, in Table 14, Quality bears very high importance while Delivery bears (only) high importance. The pairwise comparison $\mathrm{VH} / \mathrm{H}=(1,1.333,1.667$, 2.5) can be read in Table 12.

\begin{tabular}{|c|c|c|c|c|}
\hline & Quality (VH) & Delivery (H) & Service (M) & Costs (H) \\
\hline Quality (VH) & 1 & $(1,1.333,1.667,2.5)$ & $(1,2,2.5,5)$ & $(1,1.333,1.667,2.5)$ \\
\hline Delivery (H) & & 1 & $(1,1.5,1.5,4)$ & $(1,1,1,1)$ \\
\hline Service (M) & & & 1 & $(1,1 / 1.5,1 / 1.5,1 / 4)$ \\
\hline Costs (H) & & & & 1 \\
\hline
\end{tabular}

Table 14: Comparison matrix of the criteria

From Table 14, four matrices can be constructed with the corresponding low (Table 15), modal-low (Table 16), modal-upper (Table 17) and upper (Table 18) values and for each of them the criteria weights (Table 19) can be calculated with the Eigenvector method (3). 
[Post-print version] Please cite as: Alessio Ishizaka, Comparison of Fuzzy logic, AHP, FAHP and Hybrid Fuzzy AHP for new supplier selection and its performance analysis, International Journal of Integrated Supply

\begin{tabular}{|c|c|c|c|c|c|}
\hline & Quality (VH) & Delivery (H) & Service (M) & Costs (H) & Low weight \\
\hline Quality (VH) & 1 & 1 & 1 & 1 & 0.25 \\
\hline Delivery (H) & & 1 & 1 & 1 & 0.25 \\
\hline Service (M) & & & 1 & 1 & 0.25 \\
\hline Costs (H) & & & & 1 & 0.25 \\
\hline
\end{tabular}

Table 15: Criteria matrix for low weights, $\mathrm{CR}=0$

\begin{tabular}{|c|c|c|c|c|c|}
\hline & Quality (VH) & Delivery (H) & Service (M) & Costs (H) & Modal-low weight \\
\hline Quality (VH) & 1 & 1.333 & 2 & 1.333 & 0.333 \\
\hline Delivery (H) & & 1 & 1.5 & 1 & 0.25 \\
\hline Service (M) & & & 1 & $1 / 1.5$ & 0.167 \\
\hline Costs (H) & & & & 1 & 0.25 \\
\hline
\end{tabular}

Table 16: Criteria matrix for modal-low weights, $\mathrm{CR}=0$

\begin{tabular}{|c|c|c|c|c|c|}
\hline & Quality (VH) & Delivery (H) & Service (M) & Costs (H) & Modal-upper weight \\
\hline Quality (VH) & 1 & 1.667 & 2.5 & 1.667 & 0.385 \\
\hline Delivery (H) & & 1 & 1.5 & 1 & 0.231 \\
\hline Service (M) & & & 1 & $1 / 1.5$ & 0.154 \\
\hline Costs (H) & & & & 1 & 0.231 \\
\hline
\end{tabular}

Table 17: Criteria matrix for modal-upper weights, $\mathrm{CR}=0$

\begin{tabular}{|c|c|c|c|c|c|}
\hline & Quality (VH) & Delivery (H) & Service (M) & Costs (H) & Upper weight \\
\hline Quality (VH) & 1 & 2.5 & 5 & 2.5 & 0.480 \\
\hline Delivery (H) & & 1 & 4 & 1 & 0.226 \\
\hline Service (M) & & & 1 & $1 / 4$ & 0.068 \\
\hline Costs (H) & & & & 1 & 0.226 \\
\hline
\end{tabular}

Table 18: Criteria matrix for upper weights, $C R=0.02$

\begin{tabular}{|c|c|}
\hline Criteria & Fuzzy Weight \\
\hline Quality & $(0.25,0.333,0.385,0.480)$ \\
\hline Delivery & $(0.25,0.25,0.231,0.226)$ \\
\hline Service & $(0.25,0.167,0.154,0.068)$ \\
\hline Costs & $(0.25,0.25,0.231,0.226)$ \\
\hline
\end{tabular}


[Post-print version] Please cite as: Alessio Ishizaka, Comparison of Fuzzy logic, AHP, FAHP and Hybrid Fuzzy AHP for new supplier selection and its performance analysis, International Journal of Integrated Supply

Management, 9(1/2), 1-22, 2014

Table 19: Fuzzy weights

The same process is applied to calculate the sub-criteria. As Expert Choice, a software application for AHP, was not built especially for Fuzzy AHP, four hierarchies must be constructed separately. They have the same criteria and alternatives but different evaluations reflecting the four edge points of the membership function Ã (Figure 5, Figure 6, Figure 7 and Figure 8). In brackets, you can read the weights for each criteria and subcriteria.

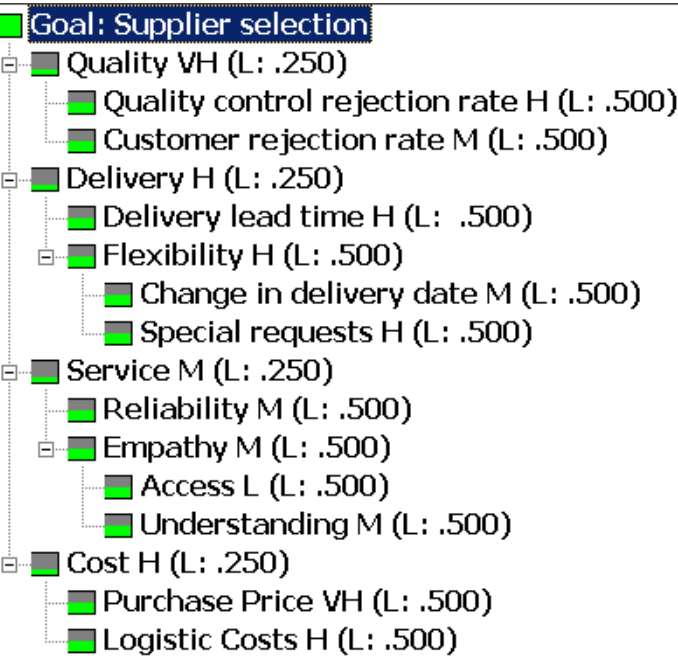

Figure 5: AHP model with lower values

\section{Goal: Supplier selection}

$-\square$ Quality VH (L: .385)

$\square$ Quality control rejection rate H (L: .600)

$\square$ Customer rejection rate $M(L:$.400)

$\square$ Delivery $\mathrm{H}$ (L: .231)

$\square$ Delivery lead time H (L: .500)

$\because \square$ Flexibility H (L: .500) $\square$ Change in delivery date M (L: .400)

$\square$ Special requests $H(L:, 600)$

Service M (L: .154)

$\square$ Reliability M (L: .500)

$\because$ Empathy M (L: .500)

$\square$ Access L (L: .100)

$\square$ Understanding M (L: .900)

Cost H (L: .231)

$\square$ Purchase Price VH (L: .625)

$\square$ Logistic Costs H (L: .375)

Figure 7: AHP model with modal-upper values

d) Calculation of the fuzzy priorities

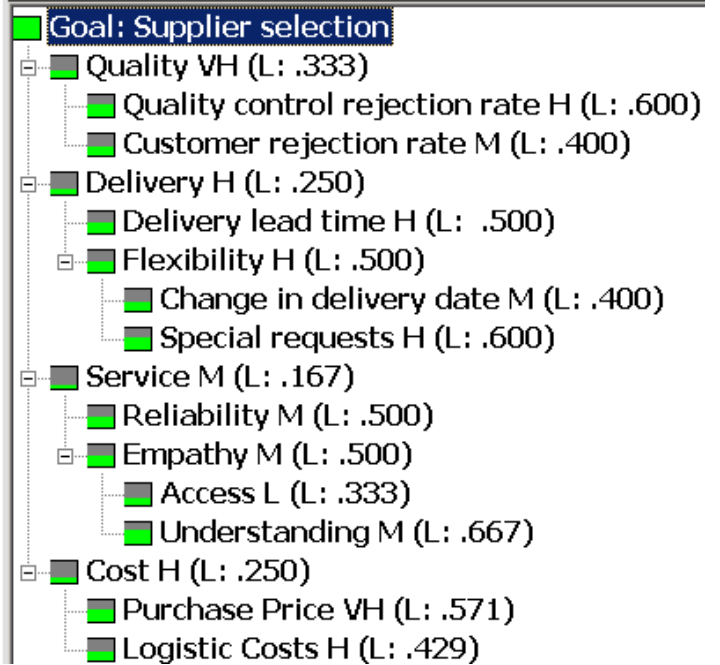

Figure 6: AHP model with modal-lower values

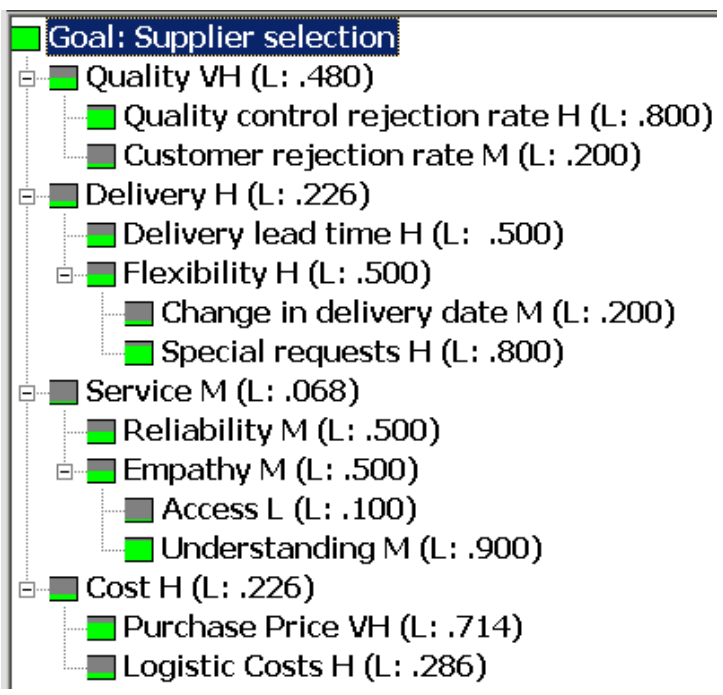

Figure 8: AHP model with upper values

Fuzzy priorities are calculated exactly in the same way criteria are calculated. The linguistic performances (Table 3) are pairwise compared (Table 13) and entered in a 
[Post-print version] Please cite as: Alessio Ishizaka, Comparison of Fuzzy logic, AHP, FAHP and Hybrid Fuzzy AHP for new supplier selection and its performance analysis, International Journal of Integrated Supply

Management, 9(1/2), 1-22, 2014

comparison matrix for each criterion. Then, they are separated in four matrices corresponding to low, modal-low, modal-upper and upper points of the membership function. The local priorities (Table 20) are then calculated for each matrix with the eigenvalue method (3).

\begin{tabular}{|l|c|c|c|}
\hline \multicolumn{1}{|c|}{ Selection criteria } & Supplier A & Supplier B & Supplier C \\
\hline Customer reject rate & $(0.333,0.222,0.200,0.095)$ & $(0.333,0.444,0.500,0.601)$ & $(0.333,0.333,0.300,0.303)$ \\
\hline Quality control reject rate & $(0.333,0.375,0.375,0.444)$ & $(0.333,0.375,0.375,0.444)$ & $(0.333,0.250,0.250,0.111)$ \\
\hline Delivery lead time & $(0.333,0.250,0.091,0.091)$ & $(0.333,0.500,0.818,0.818)$ & $(0.333,0.250,0.091,0.091)$ \\
\hline Change in delivery date & $(0.379,0.523,0.554,0.615)$ & $(0.289,0.113,0.052,0.050)$ & $(0.331,0.364,0.394,0.334)$ \\
\hline Special requests & $(0.333,0.333,0.410,0.271)$ & $(0.333,0.167,0.052,0.048)$ & $(0.333,0.500,0.538,0.682)$ \\
\hline Reliability & $(0.289,0.128,0.050,0.046)$ & $(0.331,0.276,0.334,0.243)$ & $(0.379,0.595,0.615,0.711)$ \\
\hline Access & $(0.331,0.364,0.394,0.334)$ & $(0.379,0.523,0.554,0.615)$ & $(0.289,0.113,0.052,0.050)$ \\
\hline Understanding & $(0.333,0.400,0.474,0.474)$ & $(0.333,0.200,0.053,0.053)$ & $(0.333,0.400,0.474,0.474)$ \\
\hline Purchase price & $(0.333,0.200,0.053,0.053)$ & $(0.333,0.400,0.474,0.474)$ & $(0.333,0.400,0.474,0.474)$ \\
\hline Logistics costs & $(0.333,0.500,0.538,0.682)$ & $(0.333,0.333,0.410,0.271)$ & $(0.333,0.167,0.052,0.048)$ \\
\hline
\end{tabular}

Table 20: Local fuzzy priority

The consistency ratio for each hierarchy is calculated with (5). In our case, the consistency ratios for each model are: 0 (for the lower values hierarchy), 0 (for the modal-lower values hierarchy), 0 (for the modal-upper values hierarchy), 0.03 (for the upper values hierarchy).

e) Overall priorities and defuzzification

The local priorities (Table 20) are multiplied by the criteria weights (Figure 5, Figure 6, Figure 7, Figure 8) to produce overall fuzzy priorities (second column of Table 21). The transformation of the fuzzy priorities into a crisp priority is calculated with (2) (third column of Table 21).

\begin{tabular}{|l|c|c|c|}
\hline Alternatives & Fuzzy AHP priorities & Crisp & Rank \\
\hline Supplier A & $(0.331,0.314,0.290,0.312)$ & 0.3117 & 3 \\
\hline Supplier B & $(0.333, \mathbf{0 . 3 6 0}, \mathbf{0 . 3 8 4}, \mathbf{0 . 4 2 8})$ & $\mathbf{0 . 3 7 6 3}$ & $\mathbf{1}$ \\
\hline Supplier C & $(\mathbf{0 . 3 3 6}, 0.327,0.326,0.260)$ & 0.3123 & 2 \\
\hline
\end{tabular}

Table 21: Fuzzy and crisps scores, bold is the first ranked supplier

It can been seen from Table 21 that supplier B is the best performing supplier based on the evaluation criteria and the decision maker's perception of the suppliers' performances with respect to these criteria. It is also interesting to see that the supplier $\mathrm{C}$ has a slightly higher priority value (0.336) than supplier B (0.333) on the first fuzzy edge point. However, Supplier B scores clearly much higher in the other three fuzzy priority edge points. A 
sensitivity analysis can be performed to test if the results are robust. This exercise is more intensive than in the normal AHP because four sensitivity analyses corresponding to the four hierarchies may be needed.

\section{Performance analysis}

\subsection{Introduction}

Once the suppliers selected, their performance needs to be monitored (Shen et al., 2013, Aksoy and Öztürk, 2011, Sarkar and Mohapatra, 2006). The performance criteria can either be measured directly (quantitatively), or through pairwise (qualitatively) evaluations with crisp or fuzzy values, as in the form of a mean performance and its variance. For example in Table 22, we have three type of data:

- The percentage of customer reject rate, the percentage of quality control reject rate, the number of change in delivery date and the number of special requests are given by a monthly average and variance. They are fuzzy direct values.

- Reliability, Access and understanding are evaluated on a verbal scale. They are fuzzy qualitative evaluations.

- Purchase price and logistics costs are given with crisps direct values.

\begin{tabular}{|l|c|c|c|}
\hline \multicolumn{1}{|c|}{ Selection criteria } & Supplier A & Supplier B & Supplier C \\
\hline Customer reject rate [\%] & $3 \pm 0.5$ & $1 \pm 0.2$ & $2 \pm 0.3$ \\
\hline Quality control reject rate [\%] & $1 \pm 0.2$ & $1 \pm 0.1$ & $1.5 \pm 0.3$ \\
\hline Delivery lead time [days] & $5.5 \pm 0.5$ & $2 \pm 0.3$ & $2.2 \pm 0.3$ \\
\hline Change in delivery date [\#] & $1 \pm 0.1$ & $7 \pm 0.8$ & $1.8 \pm 0.3$ \\
\hline Special requests [\#] & $3 \pm 0.5$ & $8 \pm 1$ & $2 \pm 0.3$ \\
\hline Reliability & $\mathrm{P}$ & $\mathrm{G}$ & $\mathrm{EX}$ \\
\hline Access & $\mathrm{VG}$ & $\mathrm{EX}$ & $\mathrm{P}$ \\
\hline Understanding & $\mathrm{G}$ & $\mathrm{P}$ & $\mathrm{G}$ \\
\hline Purchase price [\$/item] & 100 & 80 & 77 \\
\hline Logistics costs [\$/h] & 50 & 60 & 100 \\
\hline
\end{tabular}

Table 22: Average monthly suppliers' performance

AHP cannot accept fuzzy numbers as inputs having the form of mean and variance and fuzzy logic does not accept pairwise comparisons. Therefore we need to use a Hybrid Fuzzy AHP to solve this problem. 
[Post-print version] Please cite as: Alessio Ishizaka, Comparison of Fuzzy logic, AHP, FAHP and Hybrid Fuzzy AHP for new supplier selection and its performance analysis, International Journal of Integrated Supply Management, 9(1/2), 1-22, 2014

\subsection{Hybrid Fuzzy AHP}

The first step is to map the criteria described by mean and variance of Table 22 into fuzzy numbers. A performance depicted by mean and variance has actually three points, which correspond to a triangular or a degenerate trapezoidal (i.e. modal-low = modal-upper) membership function. Please note that all the following criteria need to be minimized: customer reject rate, the quality control reject rate, the delivery lead time, the change in delivery date, the purchase price and the logistics costs. Therefore, their performance measures need to be inverted. The complement to $100 \%$ has been calculated for the first two criteria. For example, the customer reject rate has a mean and variance of $3 \pm 0.5$, which corresponds to the three points $(2.5,3,3.5)$ or the four points $(2.5,3,3,3.5)$. As the criterion is to minimise, we take the complement to 100 , which gives the values $(96.5,97,97,97.5)$ and they are then divided by 10 to be converted in a 0-10 scale (Table 23). As delivery date, special requests, purchase price and logistics costs have also to be minimised, their complement to 10 (the highest tolerable value defined by the management) has been adopted.

\begin{tabular}{|l|c|c|c|}
\hline \multicolumn{1}{|c|}{ Selection criteria } & Supplier A & Supplier B & Supplier C \\
\hline Customer reject rate & $(9.65,9.7,9.7,9.75)$ & $(8.8,9,9,9.2)$ & $(7.7,8,8,8.3)$ \\
\hline Quality control reject rate & $(8.8,9,9,9.2)$ & $(8.9,9,9,9.1)$ & $(8.2,8.5,8.5,8.8)$ \\
\hline Delivery lead time & $(4,4.5,4.5,5)$ & $(7.7,8,8,8.3)$ & $(7.5,7.8,7.8,8.1)$ \\
\hline Change in delivery date & $(8.9,9,9,9.1)$ & $(2.2,3,3,3.8)$ & $(7.7,8.2,8.2,8.5)$ \\
\hline Special requests & $(6.5,7,7,7.5)$ & $(1,2,2,3)$ & $(7.7,8,8,8.3)$ \\
\hline Reliability & $\mathrm{P}$ & $\mathrm{G}$ & $\mathrm{EX}$ \\
\hline Access & $\mathrm{VG}$ & $\mathrm{EX}$ & $\mathrm{P}$ \\
\hline Understanding & $\mathrm{G}$ & $\mathrm{P}$ & $\mathrm{G}$ \\
\hline Purchase price & 0 & 2 & 3 \\
\hline Logistics costs & 5 & 4 & 0 \\
\hline
\end{tabular}

Table 23: Converted suppliers' performance

The linguistic performance scale for a trepezoidal membership function is given in Table 2 and their pairwise comparison in Table 13. As we have a trapezoidal membership function, four hierarchies corresponding to the low, modal-low, modal-upper and upper points are built. The criteria weights are identical to the previous model (Figure 5, Figure 6, Figure 7 and Figure 8). Only the performances of reliability, access and understanding are pairwise compared (Table 9) in a matrix. The local priorities are then calculated with the Eigenvector method (3). As the performances of all other criteria were directly measured, their local priorities are therefore exactly known. We simply need to normalise the performance of these criteria. For example, for the low point of customer reject rate in Table 23, we need to calculate the total sum: $9.65+8.8+7.7=26.15$. The normalised value, which corresponds to the local priorities, are for supplier A $9.65 / 26.15=0.369$; for supplier B 8.8/26.15=0.337; for supplier C 7.7/26.15 $=0.294$. 
[Post-print version] Please cite as: Alessio Ishizaka, Comparison of Fuzzy logic, AHP, FAHP and Hybrid Fuzzy AHP for new supplier selection and its performance analysis, International Journal of Integrated Supply Management, 9(1/2), 1-22, 2014

Table 24 contains the local priorities directly measured (Customer reject rate, Quality control reject rate, Delivery lead time, Change in delivery date, Special requests, Purchase price, Logistics costs) and derived from a pairwise comparison matrix (Reliability, Access, Understanding). We see that we have a double way to find the local priorities depending on the inputs data.

\begin{tabular}{|c|c|c|c|c|}
\hline $\begin{array}{l}\text { Selection } \\
\text { criteria }\end{array}$ & Weights & Supplier A & Supplier B & Supplier C \\
\hline $\begin{array}{l}\text { Customer } \\
\text { reject rate }\end{array}$ & $(0.125,0.199,0.096)$ & $(0.369,0.363,0.363,0.358)$ & $(0.337,0.337,0.337,0.338)$ & $(0.294,0.300,0.300,0.305)$ \\
\hline $\begin{array}{l}\text { Quality control } \\
\text { reject rate }\end{array}$ & $(0.125,0.133,0.384)$ & $(0.340,0.340,0.340,0339)$ & $(0.344,0.340,0.340,0.336)$ & $(0.317,0.321,0.321,0.325)$ \\
\hline $\begin{array}{l}\text { Delivery lead } \\
\text { time }\end{array}$ & $(0.125,0.125,0.113)$ & $(0.208,0.222,0.222,0.234)$ & $(0.396,0.394,0.394,0.388)$ & $(0.396,0.384,0.384,0.379)$ \\
\hline $\begin{array}{l}\text { Change in } \\
\text { delivery date }\end{array}$ & $(0.0625,0.05,0.0226)$ & $(0.473,0.446,0.446,0.425)$ & $(0.117,0.149,0.149,0.178)$ & $(0.410,0.406,0.406,0.397)$ \\
\hline $\begin{array}{l}\text { Special } \\
\text { requests }\end{array}$ & $(0.0625,0.075,0.1)$ & $(0.428,0.412,0.412,0.399)$ & $(0.066,0.118,0.118,0.160)$ & $(0.507,0.471,0.471,0.441)$ \\
\hline Reliability & $(0.125,0.0835,0.034)$ & $(0.049,0.143,0.050,0.046)$ & $(0.309,0.286,0.334,0.243)$ & $(0.642,0.571,0.615,0.711)$ \\
\hline Purchase price & $(0.125,0.143,0.161)$ & $(0,0,0,0)$ & $(0.377,0.377,0.377,0.377)$ & $(0.623,0.623,0.623,0.623)$ \\
\hline Logistics costs & $(0.125,0.107,0.064)$ & $(0.555,0.555,0.555,0.555)$ & $(0.444,0.444,0.444,0.444)$ & $(0,0,0,0)$ \\
\hline
\end{tabular}

Table 24: Local fuzzy priority and weights

The local priorities (Table 24) are then multiplied by the weights (Figure 5, Figure 6, Figure 7 and Figure 8) to give global fuzzy AHP priorities (second column in Table 25). The crisp value (third column in Table 25) gives the de-fuzzified value.

\begin{tabular}{|l|c|c|c|}
\hline Alternatives & Fuzzy AHP priorities & Crisp & Rank \\
\hline Supplier A & $(0.331,0.313,0.312,0.315)$ & 0.31775 & 3 \\
\hline Supplier B & $(0.333,0.327,0.317,0.325)$ & 0.3255 & 2 \\
\hline Supplier C & $\mathbf{( 0 . 3 3 6 , 0 . 3 6 , 0 . 3 1 7 , 0 . 3 5 9 )}$ & $\mathbf{0 . 3 4 3}$ & $\mathbf{1}$ \\
\hline
\end{tabular}

Table 25: Fuzzy and crisps scores, bold is the first ranked supplier

It can been seen from Table 25 that supplier $C$ is the best performing supplier based on the following evaluation criteria: the measured quantitative criteria and the decision maker's perception of the suppliers' performances. 
[Post-print version] Please cite as: Alessio Ishizaka, Comparison of Fuzzy logic, AHP, FAHP and Hybrid Fuzzy AHP for new supplier selection and its performance analysis, International Journal of Integrated Supply Management, 9(1/2), 1-22, 2014

\section{Discussion}

In this paper, we have discussed a supplier selection problem using Fuzzy logic and AHP and their following performance analysis. The presented evaluation techniques are generic and can be applied to other problems without modification. Alternatives are often measured on several criteria that are qualitative. In this case, it must be ensured that decision-makers do not have any vested interests, otherwise decisions will become biased. Experiments (Whitaker, 2007, Millet, 1997) have proven that qualitative evaluations are more precise when elicited through pairwise comparisons, as compared to the use of direct evaluations. AHP is therefore preferable when qualitative judgements are involved. Moreover, pairwise comparisons provide a possibility of analysing consistency in the provided judgements. However, it is sometimes impossible to provide an exact judgement because of the complexity, vagueness and uncertainty of the problem. For example, the decision-maker may prefer to give an evaluation between 4 and 6 instead of using exact number 5. Fuzzy numbers are the way to incorporate this imprecision. By combining both methods, Fuzzy AHP will gain the advantage of both techniques.

In some cases, criteria can be directly (quantitatively) measured. They can be crisps values or fuzzy in the sense of mean and variance. In this case, there is no need to do pairwise comparisons as their scores are exactly known. These values can be directly used to calculate the global score with its crisp or fuzzy nature.

When quantitative and qualitative, crisps and fuzzy criteria are combined; a Hybrid Fuzzy AHP can also be used. This will inherit all strengths of the two previous methods; however, this will also introduce some well-known problems of AHP:

- The judgement scale is limited, for example in the classic AHP to 9 (Donegan et al., 1992).

- The rank reversal problem (Belton and Gear, 1983) has been much debated but never fully resolved, see a review in (Ishizaka and Labib, 2009, Saaty, 2001).

- The consistency check has been criticized because it allows contradictory judgements in matrices (Kwiesielewicz and van Uden, 2004, Bana e Costa and Vansnick, 2008) or rejects reasonable matrices (Karapetrovic and Rosenbloom, 1999).

\section{Conclusion}

In order to take full advantage of an outsourcing process, selecting the best supplier is the first key step. Two approaches have been recently debated for this exercise. Ordoobadi (2009) has pointed out that linguistics evaluations are difficult to translate into numeric scales because of their vagueness, imprecision and uncertainty. Therefore, he advocates the use of Fuzzy logic. Later, Labib (2011) defends the view that AHP is superior because it allows consistency analysis, normalizing scores to sum to unity, and the ability to perform sensitivity analysis. In this paper, we have shown that scores generated through Fuzzy Logic can also be normalised to one, and sensitivity analysis can also be performed. However, we have found another significant problem in Fuzzy logic: weight of a node depends on level of decomposition. 
AHP has some drawbacks as well: it lacks the possible benefits of handling vagueness in judgements during the conversion of verbal scales into a numeric scale. In this paper, we first used Fuzzy AHP in order to capture the benefits of both methods. It offers a fuzzy conversion of the verbal scale into a numeric one and also offers a consistency analysis. As with the other two methods, it has the capability to perform sensitivity analysis which enables an understanding of the casual relationships between the criteria weights and the ranking of alternatives. The global scores can also be normalised to unity as in the others methods. Finally, we have introduced the Hybrid Fuzzy AHP, which allow integrating fuzzy or crisps, qualitative and quantitative values, whilst keeping all the benefits of AHP and fuzzy logic. However, some of the criticisms on AHP still need to be addressed.

A further area of development is the implementation of the proposed method into computer software application. It would allow an automatic fuzzy and AHP calculation, without using four models as in Expert Choice. This software would provide easy access of decision makers to the Fuzzy Analytic Hierarchy Process and contribute to propagating the method for taking better decisions.

\section{ACKNOWLEDGEMENTS}

The authors would like to thank the four reviewers for their comprehensive and thoughtful comments and suggestions.

\section{References:}

AISSAOUI, N., HAOUARI, M. \& HASSINI, E. 2007. Supplier selection and order lot sizing modeling: A review. Computers \& Operations Research, 34, 3516-3540.

AKSOY, A. \& ÖZTÜRK, N. 2011. Supplier selection and performance evaluation in just-intime production environments. Expert Systems with Applications, 38, 6351-6359.

ALTINOZ, C. 2008. Supplier selection for industry: a fuzzy rule-based scoring approach with a focus on usability. International Journal of Integrated Supply Management, 4, 303-321.

AMINDOUST, A., AHMED, S., SAGHAFINIA, A. \& BAHREININEJAD, A. 2012. Sustainable supplier selection: A ranking model based on fuzzy inference system. Applied Soft Computing, 12, 1668-1677.

BANA E COSTA, C. \& VANSNICK, J. 2008. A Critical Analysis of the Eigenvalue Method Used to Derive Priorities in AHP. European Journal of Operational Research 187, $1422-1428$.

BELTON, V. \& GEAR, A. 1983. On a Shortcoming of Saaty's Method of Analytical Hierarchies. Omega, 11, 228-230.

BRUNO, G., ESPOSITO, E., GENOVESE, A. \& PASSARO, R. 2012. AHP-based approaches for supplier evaluation: Problems and perspectives. Journal of Purchasing and Supply Management, 18, 159-172.

CHAI, J., LIU, J. \& NGAI, E. 2013. Application of decision-making techniques in supplier selection: A systematic review of literature. Expert Systems with Applications, 40, 3872-3885. 
[Post-print version] Please cite as: Alessio Ishizaka, Comparison of Fuzzy logic, AHP, FAHP and Hybrid Fuzzy AHP for new supplier selection and its performance analysis, International Journal of Integrated Supply

Management, 9(1/2), 1-22, 2014

CHERAGHI, H., DADASHZADEH, M. \& SUBRAMANIAN, M. 2004. Critical sucess factors for supplier selection: an update. Journal of Applied Business Research, 20, 91-108.

DE BOER, L., LABRO, E. \& MORLACCHI, P. 2001. A review of methods supporting supplier selection. European Journal of Purchasing \& Supply Management, 7, 75-89.

DICKSON, G. W. 1966. An analysis of vendor selection: systems and decision. Journal of Purchasing, 1, 5-17.

DONEGAN, H., DODD, F. \& MCMASTER, T. 1992. A new approach to AHP decisionmaking. The Statician 41, 295-302.

EL-SAWALHI, N., EATON, D. \& RUSTOM, R. 2007. Contractor pre-qualification model: State-of-the-art. International Journal of Project Management, 25, 465-474.

GANGA, G. \& CARPINETTI, L. 2011. A fuzzy logic approach to supply chain performance management. International Journal of Production Economics, 134, 177-187.

GAUDENZI, B. \& BORGHESI, A. 2006. Managing risks in the supply chain using the AHP method. International Journal of Logistics Management, 17, 114 - 136.

HE, T., HO, W., LEE KA MAN, C. \& XU, X. 2012. A fuzzy AHP based integer linear programming model for the multi-criteria transshipment problem. International Journal of Logistics Management, 23, 159 - 179.

HO, C. 2012. Construct factor evaluation model of Health Management Center selected by customers with Fuzzy Analytic Hierarchy Process. Expert Systems with Applications, 39, 954-959.

HO, W. 2008. Integrated analytic hierarchy process and its applications - A literature review. European Journal of Operational Research, 186, 211-228.

HOECHT, A. \& TROTT, P. 2006. Innovation risks of strategic outsourcing. Technovation, 26, 672-681.

ISHIZAKA, A. 2012. A multicriteria approach with AHP and clusters for the selection among a large number of suppliers. Pesquisa Operacional, 32, 1-15.

ISHIZAKA, A., BALKENBORG, D. \& KAPLAN, T. 2006. Influence of Aggregation and Preference Scale on Ranking a Compromise Alternative in AHP. Multidisciplinary Workshop on Advances in Preference Handling. Garda.

ISHIZAKA, A. \& LABIB, A. 2009. Analytic Hierarchy Process and Expert Choice: benefits and limitations. OR Insight, 22, 201-220.

ISHIZAKA, A. \& LABIB, A. 2011. Review of the main developments in the analytic hierarchy process. Expert Systems with Applications, 38, 14336-14345.

ISHIZAKA, A., NEMERY, P. \& PEARMAN, C. 2012. AHPSort: an AHP based method for sorting problems. International Journal of Production Research, 50, 4767-4784.

KARAPETROVIC, S. \& ROSENBLOOM, E. 1999. A Quality Control Approach to Consistency Paradoxes in AHP. European Journal of Operational Research 119, 704718.

KWIESIELEWICZ, M. \& VAN UDEN, E. 2004. Inconsistent and Contradictory Judgements in Pairwise Comparison Method in AHP. Computers and Operations Research 31, 713-719.

LABIB, A. 2011. A supplier selection model: a comparison of fuzzy logic and the analytic hierarchy process. International Journal of Production Research, 49, 6287-6299.

LIEB, R. \& BENTZ, B. 2005. The North Amarican third party logistics in 2004: the provider CEO perspective. International Journal of Physical Distribution \& Logistics Management, 35, 595-611. 
[Post-print version] Please cite as: Alessio Ishizaka, Comparison of Fuzzy logic, AHP, FAHP and Hybrid Fuzzy AHP for new supplier selection and its performance analysis, International Journal of Integrated Supply

Management, 9(1/2), 1-22, 2014

LIEB, R. \& BENTZ, B. 2006. The 3PL Industry in Asia/Pacific. Supply Chain Management Review, 10, 10-15.

LIEB, R. \& BUTNER, K. 2007. The North American Third-Party Logistics Industry in 2006: The Provider CEO Perspective. Transportation Journal, 46, 40-52.

MEIXELL, M. \& NORBIS, M. 2008. A review of the transportation mode choice and carrier selection literature. International Journal of Logistics Management, 19, 183 - 211.

MILLET, I. 1997. The effectiveness of alternative preference elicitation methods in the Analytic Hierarchy Process. Journal of Multi-Criteria Decision Analysis, 6, 41-51.

NAKANDALA, D., SAMARANAYAKE, P. \& LAU, H. 2013. A fuzzy-based decision support model for monitoring on-time delivery performance: A textile industry case study. European Journal of Operational Research, 225, 507-517.

OGDEN, J. 2006. Supply base reduction: an empirical study of critical success factors. Journal of Supply Chain Management, 42, 29-39.

ORDOOBADI, S. 2009. Development of a supplier selection model using fuzzy logic. Supply Chain Management: An international journal, 14, 314-327.

OUNNAR, F. \& PUJO, P. 2005. Evaluating suppliers within a self-organized logistical network. International Journal of Logistics Management, 16, 159 - 172.

PILTAN, M., MEHMANCHI, E. \& GHADERI, S. 2012. Proposing a decision-making model using analytical hierarchy process and fuzzy expert system for prioritizing industries in installation of combined heat and power systems. Expert Systems with Applications, $39,1124-1133$.

SAATY, T. 1977. A scaling method for priorities in hierarchical structures. Journal of Mathematical Psychology, 15, 234-281.

SAATY, T. 1980. The Analytic Hierarchy Process, New York, McGraw-Hill.

SAATY, T. 2001. The Analytic Network Process, Pittsburgh, RWS Publications.

SARKAR, A. \& MOHAPATRA, P. 2006. Evaluation of supplier capability and performance: A method for supply base reduction. Journal of Purchasing and Supply Management, 12, 148-163.

SHEN, L., OLFAT, L., GOVINDAN, K., KHODAVERDI, R. \& DIABAT, A. 2013. A fuzzy multi criteria approach for evaluating green supplier's performance in green supply chain with linguistic preferences. Resources, Conservation and Recycling, 74, 170179.

THOMAIDIS, N., NIKITAKOS, N. \& DOUNIAS, G. 2006. The evalaution of information technology projects: a fuzzy multicriteria decision-making approach. International Journal of Information Technology \& Decision Making, 5, 89-122.

VAN LAARHOVEN, P. \& PEDRYCZ, W. 1983. A fuzzy extension of Saaty's priority theory. Fuzzy Sets and Systems, 11, 199-227.

WEBER, C. A., CURRENT, J. R. \& BENTON, W. C. 1991. Vendor selection criteria and methods. European Journal of Operational Research, 50, 2-18.

WHITAKER, R. 2007. Validation examples of the Analytic Hierarchy Process and Analytic Network Process. Mathematical and Computer Modelling, 46, 840-859.

ZADEH, L. 1965. Fuzzy sets. Information and Control, 8, 338-353.

ZHENG, G., ZHU, N., TIAN, Z., CHEN, Y. \& SUN, B. 2012. Application of a trapezoidal fuzzy AHP method for work safety evaluation and early warning rating of hot and humid environments. Safety Science, 50, 228-239. 